\title{
AS PAISAGENS ENTRE TEXTOS E INTERTEXTOS
}

\author{
Landscapes between texts and intertexts
}

\author{
Leonardo Luiz Silveira da Silva \\ Doutor em Geografia pela PUC-MG \\ leoluizbh@hotmail.com
}

Artigo recebido em 18/04/2020 e aceito em 18/01/2021

DOI: $10.12957 /$ tamoios.2021.50280

\section{RESUMO}

A paisagem é um conceito polissêmico da geografia. Nas abordagens que proliferaram a partir da rejeição dos métodos neopositivistas que ascenderam na década de 1950, surgiram propostas de consideração da paisagem como um conceito que vai além da materialidade. Em meio as abordagens intersubjetivas da paisagem, disseminou-se entre um certo grupo de geógrafos a possibilidade de ver a paisagem por intermédio da metáfora paisagem-texto, e, por conseguinte, a paisagem como intertexto. $\mathrm{O}$ artigo objetiva analisar a possibilidade de avaliação das paisagens como textos e intertextos. Apontaremos também a limitação desta utilização, o que acaba por sugerir um meio do caminho metodológico entre a abordagem material e imaterial da paisagem.

Palavras-chave: Paisagem; Textos; Intertextos; Materialidade; Imaterialidade.

\begin{abstract}
The landscape is a polysemic concept of geography. In the approaches that proliferated from the rejection of the neopositivist methods that arising in the 1950s, proposals for considering the landscape as a concept that goes beyond materiality have emerged. In the midst of intersubjective approaches to landscape, the possibility of seeing the landscape through the ideia of landscape as a text metaphor was disseminated among a certain group of geographers, and therefore the landscape as an intertext. The article aims to analyze the possibility of evaluating landscapes as texts and intertexts. We will also point out the limitation of this use, which leave us to suggesting a methodological path between the material and immaterial approach to the landscape.
\end{abstract}

Keywords: Landscape; Texts; Intertexts; Materiality; Immateriality. 


\section{Introdução}

As entranhas da geografia revelam que célebres dicotomias se apresentaram e guiaram os conflitos que resultaram em uma disciplina extremamente diversa. Dentre eles destacam-se: a geografia que busca ser neutra versus a militante; os métodos da geografia física versus métodos da geografia humana (MASSEY, 2001), o método nomotético versus o método idiográfico; e, por fim, as abordagens positivistas e neopositivistas versus abordagens que rejeitam o positivismo ${ }^{1}$ (CAPEL, 2013). Estas dicotomias nos ajudam a entender as diversas correntes de pensamento geográfico que convivem hoje de forma mais ou menos harmoniosa, fazendo com que seja possível existirem em certos departamentos acadêmicos de Geografia núcleos que se apresentam isolados e que pouco dialogam com os demais profissionais que não comungam dos seus métodos. Assim, a história da Geografia se apresenta extremamente rica desde a institucionalização acadêmica, exibindo notável diversidade metodológica. Mesmo os métodos tidos como superados pelas convicções do nosso zeitgeist sobrevivem como fragmentos no corpo do pensamento geográfico, interferindo, ainda que subliminarmente, na Geografia contemporânea.

O conceito de paisagem não é imune à evolução diacrônica do pensamento geográfico. A paisagem possui abordagens diversificadas, com entendimentos que vão desde a noção reificadora dos conceitos até a fenomenológica. "A paisagem possui elasticidade e ambiguidade, necessariamente sendo impossível de apreendê-la de forma totalizante e encarcerá-la em uma definição única" (NAME, 2010, p.180). É preciso ter em mente que pensar sobre a paisagem é também refletir sobre a separação (ou não) entre o sujeito e o mundo, além da reflexão do lugar da natureza e do homem na própria paisagem (BESSE, 2008). É importante esclarecer, de partida, que a paisagem e o lugar não são a mesma coisa, mesmo quando estas categorias são definidas em parte pela presença e pelos valores dos homens que nelas vivem (MUIR, 1998), constituindo-se, deste modo, como a core área da cultura (GIL FILHO, 2005). A análise da paisagem, assim como a do lugar, não se esgota na narração de suas características materiais. As oscilações dos conceitos, que trepidaram entre a visão individual e social, bem como entre o objetivo e o subjetivo, continuam gerando problemas para aqueles que são desejosos de uma definição pura e detentora de um verniz de precisão científica ${ }^{2}$ (MACIEL, 2001). A paisagem confere ao mundo um sentido que é subordinado à experiência individual, 
sensorial e suscetível de uma elaboração estética singular. Já o conhecimento científico desafia, ao mesmo tempo, o pensamento simbólico e a experiência sensível, tendo um poderoso centro de gravidade na pretensão de objetivar o espaço sob a forma de uma extensão homogênea, isotrópica e matematizável. Deste modo, a paisagem "trata-se de uma realidade tão interior quanto exterior, tão subjetiva quanto objetiva, que se presta tanto a entrever quanto a perceber. Não é um dado objetivo, imutável, que basta ser reproduzido" (COLLOT, 2015, p.19). Congrega, portanto, natureza e cultura, materialidades e imaterialidades, relatos históricos e histórias de vida, constatações e percepções (DEUS e BARBOSA, 2017).

O amadurecimento das discussões sobre a paisagem e também sobre a cultura conceitos indissociáveis - se deu por meio de memoráveis debates acadêmicos, dentre os quais destacam-se:

- A crítica de Price e Lewis (1993a; 1993b) direcionada àqueles que criticam a suposta materialidade da obra de Sauer (2008) e à escola de Berkeley, o que estimulou respostas de Cosgrove (1993), Jackson (1993), Duncan (1993) e posteriormente Kong (1997);

- A crítica de Don Mitchell $(1995 ; 1996)$ à reificação do conceito de cultura, direcionada principalmente a autores rotulados como associados à corrente da Nova Geografia Cultural (COSGROVE, 1996; JACKSON, 1996; DUNCAN e DUNCAN, 1996);

O contexto deste fértil ambiente de debates se deu cerca de duas décadas após o florescimento da "virada cultural ${ }^{3}$ " [cultural turn] que, enquanto fenômeno intelectual espalhou sua influência em inúmeras áreas do conhecimento, produzindo um rearranjo não somente na Geografia Cultural e nos estudos da paisagem, mas amplamente na Geografia Humana. Por diversos modos, a virada cultural "tem sido positiva para a geografia, permitindo que novas teorias críticas pudessem emergir, abrindo espaço para a abordagem de tópicos que eram considerados fora do escopo da abordagem geográfica" (VALENTINE, 2001, p.167) e, ainda "ofereceu novas perspectivas para os problemas explorados pelos geógrafos culturais durante a primeira metade do século XX" (CLAVAL, 2001, p.129). Dois grandes legados para o estudo das paisagens foram deixados pela virada cultural: 
- O entendimento quase consensual de que a natureza é, por si só, uma construção cultural (COSGROVE, 1993; SCHAMA, 2009; CLAVAL, 2001);

- A oposição à reificação da cultura (MITCHELL, 1995).

A busca pelos simbolismos e pelas interpretações intersubjetivas da paisagem explica a abordagem metafórica da paisagem como um texto. O objetivo deste artigo é analisar a possibilidade de avaliação das paisagens como textos e intertextos. Apontaremos também a limitação desta utilização, o que acaba por sugerir um meio do caminho metodológico entre a abordagem material e imaterial da paisagem.

\section{O valor da abordagem metafórica e literal dos textos como ferramenta de interpretação da paisagem}

Muir (1998) salienta que a paisagem, do ponto de vista estético, é uma combinação entre arte, artefato e natureza, o que justifica a interface arte-paisagem. Paulatinamente a geografia tem se posicionado mais próxima ao estudo da arte, do trabalho dos historiadores da arte e da literatura. O poeta, por exemplo, escreve sobre coisas que também são alvo de preocupação do geógrafo: as pessoas e o seu modo de viver em certos tempos e espaços (KIRMAN, 2007). Existe uma crença já consolidada de que o uso da poesia pode se tornar um interessante instrumento de aprendizado geográfico (KIRMAN, 2007; FOSTER, 2012). Donald Meinig destacou que na Syracuse University, assim como em muitas universidades dos Estados Unidos, o departamento de geografia possui um colégio de artes e ciências, destacando o quanto que as expressões artísticas são importantes para o fazer geográfico (MEINIG, 1983). Este fato alimenta a oposição do pragmatismo objetivista à crença sobre a utilidade da subjetividade como instrumento de leitura do espaço geográfico. A proximidade entre a geografia e a arte é mal vista pelo positivismo em razão da perda da objetividade que é cara àqueles que somente veem ciência dentro de certos parâmetros. Para Bret Wallach (1997), todo trabalho de arte se constitui como uma forma de representar um fenômeno que se manifesta espacialmente a partir de escolhas pessoais do artista. Assim, Wallach se pergunta: "Todo trabalho de arte é uma construção. E toda descrição geográfica do mundo também não é?" (WALLACH, 1997, p.99). 
Silk (1984) acredita que um dos maiores benefícios do uso da literatura na interpretação geográfica é a negação das formas extremas da filosofia e metodologia positivista. Schein (1997) salienta que "uma importante consideração que emergiu destas viradas pós-positivistas na Geografia é a ideia de que a paisagem cultural é mais do que o produto final da atividade humana que poderia ser simplesmente lido como um reflexo de quem a criou" (SCHEIN, 1997, p.662). Por sua vez, Deborah Hart (1986) prefere argumentar que "a geografia literária emergiu como uma jovem subdisciplina que usou a subjetividade do romancista, poeta, dramaturgo e autobiógrafo para complementar, dilatar a abordagem, desafiar e até mesmo corrigir o empiricismo do observador orientado quantitativamente" (HART, 1986, p.191). John Fraser Hart (1982) salienta que a Geografia é ao mesmo tempo tanto arte quanto ciência, pois o entendimento do sentido de uma área não pode ser reduzido ao processo formal de investigação científica.

\section{Paisagem, tempo e texto}

Santos assim a conceitua: "A paisagem é o conjunto de formas que, num dado momento, exprime as heranças que representam as sucessivas relações localizadas entre o homem e a natureza" (SANTOS, 2012, p.103). Doreen Massey (2006), refletindo a paisagem na dimensão de sua efemeridade, a concebeu como "eventos" ou "acontecimentos" (MASSEY, 2006, p.46). Ao argumentarem que a paisagem se expressa em um dado momento, ou que se trata de um evento, atestamos a efemeridade paisagística. Se constantemente se modifica, não é a mesma paisagem que podemos observar de uma janela de uma moradia construída em topografia privilegiada. Estaríamos falando sobre paisagens, no plural. Santos (2012) diz ainda que a paisagem é "história congelada", mas que participa da "história viva". Seria história congelada porque se constitui como uma fotografia captada em um dado momento do tempo. Participaria da história viva porque as suas formas realizariam, no espaço, as funções sociais. São estas funções sociais e a dinâmica da natureza que garantem a efemeridade da paisagem. Barbara Bender prefere se referir à paisagem como um tempo em materialização: assim como o tempo, a paisagem está em constante movimento (BENDER, 2002), inexorável no seu dinamismo. Richard H. Schein, por sua vez, argumenta que a paisagem não pode ser vista simplesmente como a "soma total da história", pois o processo de leitura de paisagem deve estar "aberto ao desafio da 
agregação de novas informações e de interpretações alternativas" (SCHEIN, 1997, p.376). Em uma concepção mais rigorosa, a descrição da paisagem parece estar fadada a referir-se sempre aos tempos idos.

Por isso, concordamos que não seja tão problemático associar a paisagem à história congelada. Preferimos, contudo, a ideia de um livro a ser consultado ${ }^{4}$, que nos contaria sobre a história da própria natureza e do homem, bem como de suas relações, em escalas temporais diversas. Esta noção pode ser sintetizada pela opção de se ver a paisagem como um texto ${ }^{5}$, numa metáfora relativamente comum dentre os geógrafos culturais (ROWNTREE, 1986' ${ }^{6}$ COSGROVE e JACKSON, 1987; DUNCAN e DUNCAN, 1988). A chamada Nova Geografia Cultural revitalizou a ênfase da paisagem enquanto construção cultural que estrutura e dá significado ao mundo externo. Essas simbólicas características da paisagem produzem e sustentam um sentido social. Nesse sentido a paisagem é concebida como uma configuração de símbolos e signos, fato que fortalece metodologias que são mais interpretativas do que morfológicas. Eis a explicação para a ênfase dada na metáfora da paisagem enquanto texto (ROWNTREE, 1988). É importante observar que os textos não são inocentes; não são janelas pelas quais a realidade pode ser vista de uma forma problemática. A complexidade da leitura da paisagem e sua metáfora como texto encontra abrigo dentro da dimensão pósestruturalista, que se preocupa com os significados das palavras, expressões e ideias. No interior desta perspectiva, nenhum texto é puro, nascido livre de influências de outros textos. Por isso, é construído o axioma: todo texto é intertexto de outro texto (DUNCAN e DUNCAN, 1988). Premissas pós-estruturalistas

\footnotetext{
negam a autoria ao autor. Rejeitando a visão de que os textos são referenciais, também rejeitam a ideia de que textos são representações ou reconstruções do mundo real. Estas descrições combinam com as paisagens, pois estas não possuem autoria, embora possam ser simbólicas, não são obviamente referenciais, constituindo como criações intertextuais do leitor, assim como são produtos da sociedade que originalmente as construiu (DUNCAN e DUNCAN, 1988, p.120).
}

A paisagem pode ser analogamente ligada a um hipertexto em pelo menos dois âmbitos: no primeiro, em função dos valores que são carregados pelo seu intérprete, que são construídos “intertextualmente” devido às experiências múltiplas acumuladas espaçotemporalmente ${ }^{7}$; no segundo âmbito, em função dos diversos processos que moldam e dão forma ao arranjo paisagístico. É importante destacar que paisagem nunca é responsável por si mesma. Ela é transformada em processos que não são visíveis em sua 
escala de contemplação, replicando processos de origens externa, da mesma forma que os textos replicam ideias advindas de outros textos.

Duncan e Duncan (1988) dão enfoque a existência de "comunidades textuais", que seriam um grupo de pessoas que possuem um entendimento comum sobre um texto, seja ele falado ou lido, e que organizam aspectos de sua vida a partir do entendimento deste script. Entretanto, rejeitamos estes conceitos generalistas que querem nos fazer crer sobre o aspecto reinante de superestruturas sociais sobre as pessoas. O conceito de comunidades textuais sugere homogeneidade em indivíduos marcados pela pluralidade construída pela experiência. Entendemos que indivíduos podem - a partir de posicionamentos políticos amparados pelos mais distintos interesses - ignorar certas diferenças em prol de causas específicas. Parece, contudo, mais honesto teoricamente revelar os fundamentos da suposta homogeneidade e da sugestão de grupos que não se sustentam materialmente. Entendemos que exista um "mundo" real de coisas físicas que é independente de nossos sensos e construções mentais (PEET, 1996), desde que a palavra "mundo" não signifique totalidade ou mesmo dominância. Vale ressaltar - mesmo para aqueles que superestimam a força da base (vinculada ao arranjo das forças produtivas) e da superestrutura social como definidora das especificidades identitárias - que ambas não são fixas em si mesmo, são processuais (WILLIAMS, 2002). É interessante pensar que este caráter dinâmico da base e superestrutura social já é, em si mesmo, um indicativo da pluralidade identitária. As convicções pessoais recebem influência e moldam a superestrutura social. Por outro lado, as memórias coletivas e individuais moldam as identidades (HALBWACHS, 1990).

Interessante notar que James e Nancy Duncan relativizam suavemente as influências das superestruturas sociais no mesmo artigo, ao dizerem que "as interpretações são fruto de contextos sociais edificados por discursos históricos e culturais específicos; são construídas por comunidades interpretativas ${ }^{8}$ e frequentemente, mas nem sempre, reflete sistemas de valores hegemônicos" (DUNCAN e DUNCAN, 1988, p.120). A forma como os valores hegemônicos atingem as pessoas no âmbito individual é variada, gradativa, errática. Ao mesmo tempo, seria imprudente afirmar que numa vida em sociedade, exista alguém que suprima a influência dos valores hegemônicos. Afinal, até mesmo as escolhas alternativas podem somente serem alcançadas a partir da rejeição e fuga de elementos trazidos por experiências coletivas.

Na dimensão da analogia paisagem-texto é plausível elaborar que a paisagem é o mais completo livro sobre a história de uma dada porção da superfície terrestre. Em uma 
metáfora dentro da metáfora, salientamos que o referido livro é escrito em diversos idiomas, alguns dos quais não dominamos, fato que nos leva a não conhecer toda a história que a paisagem carrega. Analogamente os idiomas representam as técnicas de interpretação espacial, que poderiam ser simbolizadas pela datação de rochas ou a estudos arqueológicos que pudessem nos fazer entender qual era a relação entre o clima e a biosfera em eras anteriores ou, com alguma margem para dúvida, inferir de que forma vivia o homem em séculos ou milênios atrás. Estudos neste sentido já existem, mas pensamos que, com a possibilidade do avanço das técnicas e dos métodos de pesquisa, mais páginas desse livro-paisagem poderão ser decifradas. O termo história congelada pode significar, a alguém mais descuidado, uma ideia de que os elementos que compõem a paisagem explicam-se pelas suas posições e relações de momento, o que poderia excluir o aspecto diacrônico que é fundamental para descrever a paisagem tal como ela se arranja 9 .

Paulo César da Costa Gomes (2008) torna a discussão teórica aqui travada didática. $\mathrm{O}$ autor destaca que o fato do Palácio de Versalhes não possuir banheiros, pode conduzir a explicações e leituras sociológicas bizarras, afinal, a imponente construção possui onze hectares de telhados, 52.000 metros quadrados de pisos, sessenta e sete escadas, 2.153 janelas e setecentos cômodos. Uma explicação adequada sugere um mergulho na história da vida privada francesa, que nem sempre é realizada por aquele que se apresenta diante deste estranhamento (GOMES, 2008). E quanto às informações necessárias para a interpretação da paisagem que não estão disponíveis mediante os nossos registros? Seria a interpretação da paisagem um quebra-cabeça de peças faltantes?

Assumimos a importância de ressaltar que a paisagem sempre guardará uma parcela considerável dos seus mistérios. É impossível compreender a totalidade de sua evolução. Salgueiro (2001) considera que a avaliação dos elementos da paisagem em conjunto e de suas relações (método desenvolvido de forma seminal e majoritária na escola francesa da Geografia), nos levaria as ditas "dimensões ocultas da paisagem". Estas seriam associáveis ao intangível: por exemplo, as dimensões do domínio da cultura e da organização política. Contudo, é plausível considerar que nem todas estas dimensões ocultas são passíveis de serem reveladas. Andreotti (2010) reforça o raciocínio, ao argumentar, primeiramente, que se houver clareza quanto ao entendimento absoluto de uma dada porção do espaço, não estaremos nos referindo à paisagem. Do ponto de vista do indivíduo, a paisagem é "o absoluto do espírito, o absoluto da psique" (ANDREOTTI, 2010, p.269), pois a mesma revive as memórias olfativas, sonoras, táteis, além de ser 
capaz de reconstituir em nossa mente tempos idos, aludir a arranjos sociais e sistemas políticos. A paisagem reconstitui tempos e resgata espaços, pois as fatias espaciais que residem somente no plano da nossa mente não sobrevivem geodesicamente na contemporaneidade. O dinamismo da paisagem extingue certos arranjos, por isso é comum remetermos a espaços que não existem mais. As paisagens são espaços temporalmente situados e sitiados, aprisionados pelas contingências do tempo inexorável.

Existe também a dimensão oculta da história, que precisa ser levada em conta. Afinal, a paisagem é construída historicamente, tanto pela natureza quanto pelo homem. Por mais que as técnicas avançadas nos deem pistas sobre o passado e a arqueologia nos apontem linhas de interpretação sobre o pretérito humano, há de se considerar que não existe verdade histórica. Nesse sentido, as narrativas históricas seriam - vistas isoladamente ou colocadas em linhas alternativas - tentativas de mediação da realidade (BHABHA, 2013). Além da intangibilidade peculiar às influências não visíveis da paisagem destacadas por Salgueiro (2001), as tentativas de remontagem da história seriam, per si, outras faces do mistério. Na mesma linha de abordagem, Serpa (2006; 2007) alerta que nem sempre a realidade visível esclarece completamente o que de fato acontece no espaço. Concluímos neste ponto que a paisagem guarda mistérios e o seu nível de compreensão será sempre parcial frente ao conjunto de informações que são carregadas pelos seus elementos constituintes.

Consideramos problemático tratar a paisagem como história viva, como fez Milton Santos, ainda que seja relativamente comum na literatura acadêmica este tratamento dado à categoria em questão. As funções sociais realizadas pelas formas da paisagem são passíveis de ser levadas em conta até o momento em que a paisagem é percebida ou descrita. Se a paisagem é expressa em um "dado momento", tempos futuros podem não compor parcela importante do seu sentido epistemológico. São importantes, obviamente, para quem planeja e vive o espaço. Assim, o ato de descrição ou percepção da paisagem é, contrariamente à noção de história viva, o "encerramento da história" 10 enquanto discurso ou descrição. A descrição/percepção da paisagem, voltando à analogia anterior da paisagem enquanto livro, é a entrega do texto para uma editora. Trata-se da arte final de uma obra construída ao longo do tempo, mas que está sendo encerrada. Obviamente o espaço geográfico é sensível ao tempo e a paisagem se modificará. A rigor, após o encerramento da descrição da paisagem, estaremos diante de outra paisagem, vítima do seu processo contínuo de transformação. Ao comparar as mudanças entre o passado e o presente estaremos comparando "paisagens", no plural. Nestes termos, a 
excepcionalidade da paisagem é tamanha que deveria ser muito mais comum lermos e ouvirmos a palavra paisagens (plural) do que paisagem (singular).

Poderiam rebater nosso preciosismo àqueles que apresentam um sentido da paisagem descompromissado com o seu recorte temporal: afinal, a paisagem é polissêmica e depende da abordagem das diferentes correntes da Geografia ou da própria evolução do conceito. Acreditamos que, independente da corrente da Geografia, qualquer descrição que se afasta do recorte temporal para possibilitar a percepção e a descrição da paisagem, metaforiza a mesma, até mesmo romantizando-a. Quanto à evolução do conceito, se faz necessária a permanente reflexão epistemológica, com base nos fundamentos mais modernos da ciência geográfica. Afinal, au contraire, estaríamos ainda hoje confundindo o escopo semântico de território e região, devido à sua congruência semântica pretérita. Há de considerar que o sentido das palavras está em movimento e o senso comum pode interferir no mesmo, ainda que, em determinados casos, com certas restrições. Afinal, parece existir relativo monopólio daqueles que definem o significado de cromossomos ou de átomos, deixando pouca margem de flexibilização dos seus significados.

\section{Paisagens e Intertextos}

Os textos literários não podem ser entendidos como completamente autorais. Os textos são construções intertextuais, compreensíveis somente nos termos de outros textos (CULLER, 1976). A intertextualidade, que é um dos termos mais utilizados no vocabulário crítico contemporâneo (ALLEN, 2000), “enfatiza que ler é colocar um trabalho em um espaço discursivo, relacionando-o a outros textos e códigos desse espaço. Escrever também é uma atividade similar: é assumir uma posição em um espaço discursivo" (CULLER, 1976, p.1383). Em uma abordagem e título provocativos, Paul Olsson (1983) publicou o manifesto intertextual Expressed Impressions of Impressed Expressions. O autor nos aponta que um texto é uma textura de palavras. Para ele, nenhuma palavra é uma nova palavra, pois são oriundas de outros textos e contextos. Assim, todas as expressões carregam múltiplas imagens: aquilo que é lembrado, desmembrado e, às vezes, apagado. No seu apego a intertextualidade e à desconstrução, o autor ainda provoca: "cidades são metáforas e teorias das cidades são metáforas das 
metáforas", concluído a posteriori que "teorias são metáforas de metáforas" (OLSSON, 1983, p.61; p.63).

Se a paisagem pode ser vista como um texto, deve também ser vista como um intertexto, ou seja, o texto paisagístico possui interface com outros textos. Há três planos de justificativa para compreendermos a intertextualidade da paisagem:

- Plano da intertextualidade literal: a expressão da paisagem por meio da linguagem apresenta interface com outros textos, não só sobre a paisagem descrita ou genericamente sobre paisagens, mas sobre qualquer abordagem;

- Plano da intertextualidade metafórica: a paisagem pode ser vista como um texto a ser lido; sua expressão é um texto produzido. Neste plano, como nos lembra Halbwachs (1990), a interpretação da paisagem é guiada diacronicamente pela experiência humana, moldada pela memória individual e coletiva. A intertextualidade se manifesta, na dimensão metafórica, por intermédio da dependência das identidades (e do conjunto de valores e preferências carregados pelo indivíduo) frente à vida em sociedade. Ainda que desacreditemos no determinismo de uma superestrutura social capaz de criar uma massa monolítica de sujeitos, é inegável a força da influência da vida em sociedade na composição identitária. Assim, da mesma forma que textos são compreendidos por outros textos, a paisagem é individualmente percebida e expressa (ações que não são completamente congruentes) pela força da influência das experiências sociais

- Plano na intertextualidade espaço-temporal: é plausível considerar que a paisagem percebida em um plano material e mesmo imaterial não se explica enquanto fotografia: são necessários o entendimento de processos além de sua escala de análise para a sua compreensão e eventos ocorridos em tempos idos que somente deixaram suas cicatrizes. Nesta metáfora, salientamos que a intertextualidade paisagística nos leva a crer que uma explicação mais aprofundada sobre o espaço observado envolve o conhecimento de outro lugar e de outro tempo, como textos nem sempre acessíveis aos intérpretes. 
Quanto à capacidade da obra de retratar fielmente a paisagem, Pocock (1988) argumenta que o texto nunca se apresenta como uma janela transparente para o mundo, e o mesmo acontece com a pintura. "Sempre haverá um lado escuro da paisagem não contemplado pela mensagem, seja do texto ou da pintura" (PORTEOUS, 1988, p.95). Esta visão é compartilhada por Judy Walton que diz que os textos não espelham a paisagem, por serem construções intertextuais abertos à multiplicidade de significados e leituras (WALTON, 1995, p.63). Todavia, a literatura consagra-se como uma fonte inegável de acesso à informação paisagística, sem a pretensão de esgotar a sua descrição ou se constituir como um espelho. Por isso confiamos, dentre outros exemplos literários, na força da obra de João Guimarães Rosa como um instrumento de auxílio do leitor à compreensão de certos elementos do sertão de Minas Gerais em parte do século XX (Evangelista e Travassos, 2019).

\section{Críticas à paisagem como textos e intertextos}

Apresentamos três questões recorrentes quanto à utilização acadêmica da metáfora da paisagem como texto:

- As indagações sobre a possibilidade de se utilizar o texto para a compreensão da mediação entre o autor e a paisagem, visto que o texto poderia ser uma mera obra de ficção desvinculada das impressões do autor (chamaremos este tópico de "a questão do eu-lírico");

- Os questionamentos acerca da capacidade do texto de mediar a materialidade e a imaterialidade da paisagem;

- A crítica quanto a multiplicidade de conexões intertextuais que esvaziariam a utilidade da metáfora paisagem-texto como ferramenta interpretativa.

\section{A questão do eu-lírico}

É obsoleta a questão de saber se no discurso literário - tanto poético como romanesco - o autor como pessoa está ausente e o "eu" é um puro sujeito da enunciação (Combe, 2010). "A gênese do conceito de "sujeito lírico" é, portanto, inseparável da 
questão das relações entre literatura e biografia, e do problema da "referencialidade" da obra literária. O poeta lírico não se opõe tanto ao autor quanto ao autobiógrafo como sujeito da enunciação e do enunciado" (COMBE, 2010, p.120). Esta é uma questão similar a do pintor e de sua obra. Um protagonista criado em um romance, por mais que exiba características que representem a oposição aos valores do escritor, é dependente das experiências do seu criador intelectual. O antagonismo dos valores somente será reconhecido pelo autor se o mesmo partir das bases dos seus próprios princípios e valores. Michel Collot preferiu uma abordagem menos determinante da questão, ao salientar que "quase nenhuma obra literária deixa de refletir, ainda que diretamente, as circunstâncias do lugar de existência do escritor" (COLLOT, 2012, p.22). Portanto, o receio do deslocamento entre obra e autor é infundado.

\section{Entre materialidade e a imaterialidade}

A metáfora da paisagem enquanto texto, para alguns, precisa ser aplicada, vista, desenvolvida e teorizada com parcimônia. Don Mitchell (1993) em uma resenha crítica do livro de Barnes e Duncan ${ }^{11}$ (1992) argumentou que a utilização da metáfora textual fez com que os autores construíssem uma argumentação que desenhavam duas possibilidades paralelas e antagônicas da interpretação paisagística: de um lado, a interpretação meramente material, a bruta realidade; de outro, o mundo dos textos, discurso, metáfora e da linguagem. Mitchell salienta que esta é uma falha grave na teoria, pois, trata-se de uma "posição frustrante, uma vez que o que precisa ser teorizado são as complexas interações entre a materialidade e ideias. Palavras e discursos são amarrados ao mundo por poderosos atores sociais" (MITCHELL, 1993, p.474). Walton (1995) discordou da crítica de Mitchell em uma publicação no periódico Professional Geographer, ao argumentar que a utilização da metáfora da paisagem como texto não implica necessariamente em uma ontologia idealista (WALTON, 1995, p.62). Independente se Mitchell tem ou não razão em sua crítica, acreditamos que uma abordagem assertiva da paisagem passa pela incorporação de sua materialidade e imaterialidade, em algum ponto de equilíbrio entre a objetividade e subjetividade, o que não é o mesmo que defender uma visão pragmática e positivista da paisagem. Desta forma, a metáfora paisagem-texto não pode ser entendida como um convite à negação absoluta da materialidade. Augustin Berque (2012) oferece uma solução conceitual para 
o lidar com a mediação entre a materialidade e a imaterialidade: os geogramas, que seriam os elementos que transcendem a materialidade. "As coisas, no ecúmeno, conciliam dinamicamente o material e o imaterial. Essa dinâmica é o que chamei de "trajeção", neste caso, significando que a realidade vai além do material, ao mesmo tempo retornando a ele também” (BERQUE, 2012, p.7).

\section{A fraqueza da intertextualidade}

James Duncan (1995) apontou que a fraqueza da metáfora intertextual reside no fato de que em muitas instâncias, as complexas conexões intertextuais são imensamente difíceis de serem dimensionadas ou percebidas (Duncan $\left.{ }^{12}, 1995\right)$. Não entendemos isto como fraqueza. A pretensão de dimensionar o universo das conexões intertextuais é utópica tanto na dimensão literal da intertextualidade quanto na dimensão metafórica da paisagem como texto. De maneira semelhante, as narrativas históricas alternativas às grandes narrativas (metanarrativas) não podem se posicionar como detentoras da verdade. Grosseiramente, é razoável asseverar que é quixotesca a batalha a favor do dimensionamento da realidade, do esgotamento das narrativas e do estabelecimento da verdade. As virtudes intertextuais se apresentam justamente na possibilidade de buscar as múltiplas conexões textuais que enriquecem nossa compreensão, de forma similar ao nobre exercício de intermediação de narrativas que ajudam a enriquecer a abordagem histórica.

\section{Considerações finais}

A metáfora da paisagem-texto que também abriga a possibilidade de ver a categoria geográfica em questão como intertexto, somente pode ser desenvolvida no contexto da rejeição de formas positivistas de explicação (Smith, 1979). Isto ocorre devido a necessária consideração da intersubjetividade que guia os significados paisagísticos. Em meio ao quid pro quo entre Mitchell (1995; 1996) e Cosgrove (1996), um importante consenso foi alcançado: que o ponto ótimo da interpretação da cultura, bem como da paisagem, passa pela mediação entre a materialidade e a imaterialidade, ação que consegue ser sintetizada conceitualmente na ideia de geogramas, conceito 
cunhado por Augustin Berque (2012). É justamente na possibilidade de negar toda materialidade a partir da diversidade das formas discursivas que reside o constrangimento da utilização da metáfora paisagem-texto. É possível, contudo, fazer uso das narrativas descritivas e apropriá-las de forma a mediar o plano das ideias e a substância material (Ingold, 1993).

A análise intertextual das narrativas é uma metáfora dentro de outra metáfora, sendo muito poderosa para aludir as diferenças entre os percursos das experiências individuais, replicadas por intermédio de um processo de formação identitária marcada pela repetição-com-diferença e reciprocidade-sem-começo, tal como nos instrui Stuart Hall (2013). Não podemos, todavia, ter a pretensão de usarmos os intertextos para dimensionar o todo intangível, protagonizar metanarrativas e sermos os portadores da verdade utópica.

\begin{abstract}
Notas
${ }^{1}$ Algumas das quais são chamadas de pós-positivistas, tal como foram tratadas por Neil Smith (1979).

${ }^{2}$ A discussão sobre o caráter científico da geografia acompanha a disciplina desde os primórdios de sua institucionalização. Após a consolidação da chamada nova geografia (também chamada de geografia quantitativa ou pragmática), que se desenvolveu na década de 1950, a busca desenfreada pela validade dos argumentos centrou-se no cânone da metodologia positivista. De uma forma até mesmo cômica, John Fraser Hart evidencia que a obsessão positivista (revitalizada nos anos 1950 com o neologismo "neo"positivismo) manifestou ações para além do método científico: "Essas pessoas tem feito algumas coisas estranhas na tentativa de se parecerem mais "científicas". Por um tempo, exemplificando, estava muito na moda entre os geógrafos utilizarem botas que iam até os joelhos e camisetas de flanelas vermelhas no intuito de se parecerem como geólogos, a quem consideravam serem mais cientistas do que os geógrafos. Mais recentemente, a moda entre alguns geógrafos tem sido se vincularem às salas de computadores numa tentativa de se parecerem como economistas" (HART, 1982, p.3).

${ }^{3}$ A virada cultural possui como marca a rejeição de epistemologias positivistas e tem como ênfase os estudos sobre os significados. O pós-modernismo, pós-colonialismo e pós-estruturalismo ajudam a consolidar os seus paradigmas. A virada cultural mobilizou o complexo arcabouço que busca relacionar a antropologia, a psicologia, a linguística, a filosofia e a arte para a compreensão da cultura (PEDROSA, 2016).

${ }^{4}$ Meredith (1985) utiliza a expressão "biografia da paisagem" para se remeter ao processo de evolução da mesma. A noção de uma biografia da paisagem "comporta as vontades individuais do povo que fez escolhas durante o processo de evolução da paisagem" o que explicaria o seu arranjo contemporâneo. "Indivíduos não podem operar fora dos ambientes socioeconômicos e físicos, mas podem mediar as interações entre ambos. Esta habilidade cria a biografia das paisagens" (MEREDITH, 1985, p.46).

${ }^{5}$ Em certas abordagens antropológicas, o conceito de cultura também é tratado metaforicamente como um texto (NAME, 2010).

${ }^{6}$ Lester Rowntree destaca três alertas no uso da metáfora da paisagem como texto: o primeiro alerta referese às discrepâncias existentes entre a paisagem descrita por um intérprete e a percepção dos seus "leitores"; o segundo alerta é o risco de privar a contínua interação entre os elementos da paisagem, estabelecendo um produto estático e acabado; o terceiro é o grau de dificuldade de se compreender (por parte do interlocutor) como se levou a interpretar o texto paisagem de uma dada forma (ROWNTREE, 1986, p.582). Não vemos sentido no primeiro e no terceiro alerta, pois, o estranhamento perceptivo é o apanágio da paisagem percebida individualmente. Já partimos do pressuposto que as diferenças de percepção paisagística remetem às diferenças identitárias e experienciais carregadas por cada indivíduo. Não faz sentido pensar que Rowntree ressinta da materialização ontológico-positivista que é estranha à paisagem como espaço a ser percebido. Afinal, o segundo alerta, ao qual concordamos, destaca o fato de que a paisagem como texto
\end{abstract}


pode colaborar para a construção de uma visão que a reifique. Nesse sentido, é importante destacar que todo "texto paisagístico" já nasce caduco.

7 A paisagem como portadora de hipertextos permitiria a leitura de tempos pretéritos por meio de iconografias representativas de tais tempos (CARVALHO, 2017). É como consultar uma arquitetura que caiu em desuso e compreender as razões de sua obsolescência.

${ }^{8} \mathrm{O}$ termo comunidades interpretativas carrega ambiguidade importante de ser abordada. Pode carregar, pelo menos, dois sentidos antagônicos: o primeiro, uma comunidade que interpreta da mesma forma os textos e a paisagem, o que aproximaria do sentido de "comunidades textuais"; o segundo, uma comunidade que confronta, elabora e permanentemente modifica os significados à luz da experiência social, sem que com isso os indivíduos massifiquem o pensar.

${ }^{9}$ Sobre a dimensão não percebida da evolução da paisagem, assim argumenta Pierre George: "Em qualquer procedimento geográfico, o primeiro passo é a observação. Todavia, o comportamento normal da observação consiste em propor problemas que deverão ser resolvidos pela explicação. Parte desses problemas provém de dados que escapam ao alcance da observação, quer por se tratar de dados pertencentes ao passado e dos quais só se pode observar os efeitos, quer pelo fato de ser necessário levar em conta certas impulsões invisíveis e muitas vezes oriundas de centros de comando exteriores ao meio imediatamente considerado. Contudo, o visível e o invisível possuem algo em comum: pelo menos até certo ponto, tanto um como o outro são responsáveis pela dimensão. Por outro lado, existe uma margem de interferência entre o visível e o invisível quando certas situações e estruturas ocasionam afloramentos exteriorizados, susceptíveis de observação embora seu conhecimento dependa, quanto ao conjunto, muito mais de investigações, de pesquisas de laboratório e estatísticas" (GEORGE, 1978, p.20-21). Argumenta ainda o geógrafo francês que estas pesquisas permitir-nos-íamos, por intermédio do método comparativo, a elaboração de "hipóteses de generalização", que seriam guiadas, por sua vez, pela extrapolação de um dado tido como significativo (GEORGE, 1978).

${ }^{10}$ Qualquer historiador que escreve um livro de história geral terá a exata noção de que o último capítulo que verse sobre a história contemporânea não decreta que a história não estará mais em movimento. Contudo, ao escrever um livro dessa natureza, é necessário fazer uma escolha de corte temporal. Ao contrário, a mercê da passagem do tempo, um historiador jamais poderia concluir um livro. O mesmo processo ocorre com o geógrafo que percebe/descreve a paisagem. Não se pode determinar o futuro, dada a complexidade de fatores que guiam a transformação do espaço. Assim, o ato de perceber ou descrever a paisagem se enquadra, stricto sensu, em um recorte temporal.

${ }^{11}$ BARNES, T. J; DUNCAN, J. Writing Worlds: Discourse, text and metaphor in the representation of landscape. New York: Rourtledge, 2016, 282p.

12 Apesar do apontamento sobre a fraqueza da intertextualidade, James Duncan é um dos grandes divulgadores da metáfora da paisagem como texto, imortalizada no seu livro. Ver: DUNCAN, James. The city as a text:. The Politics of Landscape Interpretation in the Kandya Kingdom. Cambridge: Cambridge University Press, 1990, 265p.

\section{Referências}

ALLEN, Graham. Intertextuality: the new critical idiom. London and New York: Routledge, 2000.

ANDREOTTI, Giuliana. Paisagens do espírito: a encenação da alma. Ateliê Geográfico, v.4, n.4, p.264280, 2010.

BARNES, Trevor J; DUNCAN, James S. Writing Worlds: Discourse, Text and Metaphor in the Representation of Landscape. London and New York: Routledge, 1992.

BENDER, Barbara. Time and landscape. Current Anthropology, v.43, supplement, aug-oct, p.103-112, 2002.

BERQUE, Augustin. Geogramas, por uma ontologia dos fatos geográficos. Geograficidade, v.2, n.1, verão, p.4-12, 2012.

BESSE, Jean-Marc. Landscape: between loss and history. Critique d’art, n.32, automne, 2008.

BHABHA, Homy. O local da cultura. Belo Horizonte: Editora UFMG, 2013. 
CARVALHO, José Luiz de. Denis Cosgrove e o desenvolvimento da perspectiva simbólica e iconográfica da paisagem. Geograficidade, v.7, n.2, p.87-97, 2017.

CAPEL, Horácio. Neopositivismo e Geografia Quantitativa. (in): Capel, Horacio. Ruptura e continuidade no pensamento geográfico. Maringá: EDUEM, 2013.

CLAVAL, Paul. The cultural approach and geography - the perspective of communication. Norsk Geografisk Tidsskrift - Norwegian Journal of Geography, v.55, n.3, p.126-137, 2001.

COLLOT, Michel. Rumo a uma geografia literária. Gragoatá, n.33, 2ºmestre, p.17-31, 2012.

COMBE, Dominique. A referência desdobrada: o sujeito lírico entre a ficção e a autobiografia. Revista USP, n.84, dezembro-fevereiro, p.112-128, 2009-2010.

COSGROVE, Denis; JACKSON, Peter. New Directions in Cultural Geography. Area, vol.19, n.2, jun, p.95-101, 1987.

COSGROVE, Denis. On "the reinvention of Cultural geography" by Price and Lewis. Annals of the Association of American Geographers, v.83, n.3, p.515-517, 1993.

COSGROVE, Denis. Ideas and culture: a response to Mitchell. Transactions of the Institute of British Geographers. V.21, p.574-575, 1996.

CULLER, Jonathan. Presupposition and Intertextuality. Comparative Literature, v.91, n.6, december, p.13801396, 1976.

DEUS, José Antônio Souza de; BARBOSA, Liliane de Deus. Uma contribuição ao estudo da paisagem nas regiões de antiga mineração do Brasil na ótica das geografias cultural e histórica. Geografias, v.15, n.2, p.38-49, 2017.

DUNCAN, James. The city as a text:.The Politics of Landscape Interpretation in the Kandya Kingdom. Cambridge: Cambridge University Press, 1990.

DUNCAN, James. Commentary. Annals of the Association of American Geographers, v.83, n.3, p.517$519,1993$.

DUNCAN, James. Landscape Geography, 1993-1994. Progress in Human Geography, v.19, n.3, p.414422, 1995.

DUNCAN, James; Duncan, Nancy. (Re)reading the landscape. Environmental and Planning D. Society and Space. v.6, p.117-126, 1988.

DUNCAN, James; DUNCAN, Nancy. Reconceptualizing the Idea of Culture in Geography: A Reply to Don Mitchell. Transactions of the Institute of British Geographers, New Series, v.21, n.3, p.576-579, 1996.

EVANGELISTA P, Vania Kele; TRAVASSOS, Luiz Eduardo Panisset. Geografia, paisagem, literatura e geopatrimônio nas obras de Guimarães Rosa. Ateliê Geográfico, v.13, n.3, dez., p.112-137, 2019.

GEORGE, Pierre. Os Métodos da Geografia. São Paulo: Difel, 1978.

GIL FILHO, Sylvio Fausto. Geografia cultural: estrutura e primado das representações. Espaço e Cultura, UERJ, n.19-20, jan./dez., p.51-59, 2005.

GOMES, Paulo César da Costa. "Versalhes não tem banheiros!” As vocações da geografia cultural. Espaço e Cultura, UERJ, edição comemorativa, p.175-183, 2008.

FOSTER, Ellen J. Finding Geography Using Found Poetry. The Geography Teacher, v.9, n.1, p.26-29, 2012. 
HALBWACHS, Maurice. A Memória Coletiva. São Paulo: Editora Vértice, 1990.

HALL, Stuart. Pensando a diáspora: reflexões sobre a terra no exterior (in): Hall, Stuart - Sovik, Liv (org.). Da diáspora: identidades e mediações culturais. Belo Horizonte: Ed.UFMG, 2013.

HART, Deborah. A Literary Geography of Soweto. Geojournal, v.12, n.2, p.191-195, 1986.

HART, John Fraser. Highest form of the Geographer's Art. Annals of the Association of American Geographers. V.72, i.1, march, p. 1-29, 1982.

INGOLD, Tim. The temporality of the landscape. World Archaelogy, v.25, n.2, p.152-174, 1993.

JACKSON, Peter. Berkeley and Beyond: Broadening the Horizons of Cultural Geography. Annals of the Association of American Geographers, v.83, n.3, p.519-520, 1993.

JACKSON, Peter. The idea of culture: a response to Don Mitchell. Transactions of the Institute of British Geographers, v.21, p.572-573, 1996.

KIRMAN, Joseph M. Aesthetics in Geography: Ideas for Teaching Geography Using Poetry. Journal of Geography, V.106, n.5, p.207-214, 2007.

KONG, Lily L. L. A “new” cultural geography? Debates about invention and reinvention. Scottish Geographical Magazine, v.113, n.3, p.177-185, 1997.

MACIEL, Caio Augusto Amorim. Morfologia da Paisagem e imaginário geográfico: uma encruzilhada onto-gnoseológica. Geographia, v.3, n.6, p.1-12, 2001.

MASSEY, Doreen. Talking of space-time. Transactions of the Institute of British Geographers, New series, v.26, n.2, p.257-261, 2001.

MASSEY, Doreen. Landscape as provocation. Journal of Material Culture, v.11, n.1, p.33-48, 2006.

MEINIG, Donald W. Geography as an art. Transactions of the Institute of British Geographers, New Series, v.8, n.3, p.314-328, 1983.

MEREDITH, T. The upper Columbia valley, 1900-1920: an assessment of "boosterism" and the "biography of landscape". Canadian Geographer, n.29, p.44-55, 1985.

MITCHELL, Don. Book review of Writing Worlds: Professional Geographer, v.45, i.4, p.474-475, 1993.

MITCHELL, Don. There's No Such Thing as Culture: Towards a Reconceptualization of the Idea of Culture in Geography. Transactions of the Institute of British Geographers. New Series, v.20, n.1, p.102-116, 1995.

MITCHELL, Don. Explanation in Cultural Geography: A Reply to Cosgrove, Jackson and the Duncans. Transactions of the Institute of British Geographers. v.21, n.3, p.580-582, 1996.

MUIR, Richard. Landscape: a wasted legacy. Area, v.30, n.3, p.263-271, 1998.

NAME, Leo. O conceito de paisagem na geografia e sua relação com o conceito de cultura. Geotextos, v.6, n.2, dez., p.163-186, 2010.

OLSSON, Paul Gunnar. Expressed Impressions of Impressed Expressions. Geographical Analysis, vol.5, n.1, January, p.60-64, 1983.

PEDROSA, Breno Viotto. O império da representação: a virada cultural e a geografia. Espaço e Cultura, UERJ, n.39, jan./jun, p.31-58, 2016.

PEET, Richard. Discursive idealism in the "landscape-as-text" school. Professional Geographer, v.48, n.1, p.96-98, 1996. 
POCOCK, Douglas C. D. Geography and Literature. Progress in Human Geography, v.12, Issue 1, march, p.87-102, 1988.

PORTEOUS, J. Douglas. Planned to death: the annihilation of a place called Howdendyke. Toronto: University of Toronto Press, 1988.

PRICE, Marie; LEWIS, Martin. The Reivention of Cultural Geography. Annals of the Association of American Geographers, v.83, n.1, p.1-17, 1993a.

PRICE, Marie; LEWIS, Martin. Reply: On Reading Cultural Geography. Annals of the Association of American Geographers, v.83, n.3, p.520-522, 1993b.

ROWNTREE, Lester. Cultural/humanistic geography. Progress in Human Geography, v.10, n.4, p.580$586,1986$.

ROWNTREE, Lester. Orthodoxy and new directions: cultural/humanistic geography. Progress in Human Geography, v.12, n.4, p.575-586, 1988.

SALGUEIRO, Teresa Barata. Paisagem e Geografia. Lisboa: Finisterra, número 72, p.37-53, 2001.

SANTOS, Milton. A Natureza do Espaço. São Paulo: Edusp, 2012.

SAUER, Carl. A morfologia da paisagem. (in): Oakes, Timothy S; Price, Patricia L (eds). The Cultural Geography Reader. New York: Routledge, 2008.

SCHAMA, Simon. Paisagem e Memória. São Paulo: Companhia das Letras, 2009.

SCHEIN, Richard H. The Place of landscape: A Conceptual Framework for interpreting an American Scene. Annals of the Association of American Geographers, v.87, n.4, p.660-680, 1997.

SERPA, Angelo. O Trabalho de Campo em Geografia: Uma abordagem Teórico-Metodológica. São Paulo: Boletim Paulista de Geografia, v.84, p. 7-24, 2006.

SERPA, Angelo. Parâmetros para a construção de uma crítica dialético-fenomenológica da paisagem contemporânea. Presidente Prudente: Revista formação, n.14, v.2, p.14-22, 2007.

SILK, J. Beyond Geography and Literature. Environmental and Planning D: Society and Space, v.2, p.151-178, 1984.

SMITH, Neil. Geography, science and post-positivist modes of explanation. Progress in Human Geography, v.3, i.3, September, p.356-383, 1979.

VALENTINE, Gill. Whatever happened to the social? Reflections on the "cultural turn" in British Human Geography. Norwegian Journal of Geography, v.55, p.166-172, 2001.

WALLACH, Bret. Painting, Art History, and Geography. Geographical Review, v.87, n.1, January, p.9299, 1997.

WALtON, Judy R. How Real(ist) can you get? Professional Geographer, v.47, i.1, p.61-65, 1995.

WILLIAMS, Raymond. Base e estrutura na teoria cultural marxista, Espaço e Cultura, UERJ, n.14, p.721, jul-dez de 2002. 